\title{
Öğrencilerin Toplumsal Cinsiyet Rollerine İlişkin Tutumların Belirlenmesi Üzerine Bir Alan Araştırması
}

\section{Yılmaz DAŞLI*}

Öz: Araştırmanın amacı öğrencilerin toplumsal cinsiyet rol tutumlarını ve etkileyen faktörlerin belirlenmesidir. Araştırma, Sivas Cumhuriyet Üniversitesi Eğitim Fakültesinde yapılmıştır. Araştırmanın evren sayısı bilindiği için örneklem hesabı yapılmış ve 350 kişi araştırmaya alınmıştır. Araştırmanın verileri Kişisel Bilgi Formu ve Toplumsal Cinsiyet Rolleri Tutum Ölçeği (TCRTÖ) kullanılarak toplanmıştır. Veriler SPSS 22 programında değerlendirilmiştir. Öğrencilerin \%73,7’si Türk toplumunda kadın ve erkeğin eşit haklara sahip olmadığını, \% 65,4'ü inin bu eşitsizliğin toplumsal yapıdan olduğunu ve \% 39,7'si toplumsal cinsiyet ayrımcılığını yaşadığını belirtmiştir. Kız öğrencilerin TCRTÖ toplam puan ortalamasının erkeklerden istatistiksel olarak anlamlı düzeyde yüksek olduğu saptanmıştır $(p<0.05)$. Öğrencilerin anne eğitim durumlarına göre toplumsal cinsiyet rolleri alt boyutlarında istatistiksel olarak anlamlı bir fark saptanamamıştır $(\mathrm{p}>0.05)$. Buna karşın baba eğitim durumlarına göre eşitlikçi cinsiyet rolü, kadın cinsiyet rolü, geleneksel cinsiyet rolü ve erkek cinsiyet rolüdür alt boyut puan ortalaması arasında istatistiksel olarak anlamlı bir fark olduğu belirlenmiştir $(p<0.05)$. Çalışmada yer alan öğrencilerin genel olarak eşitlikçi toplumsal cinsiyet rol tutuma sahip oldukları bulunmuştur. Diğer taraftan kız öğrencilerin erkek öğrencilere nazaran daha yüksek oranda eşitlikçi toplumsal cinsiyet rol ve tutumlarına sahip oldukları tespit edilmiştir. Çalışmaya katılan öğrencilerin dörtte üçü kadın erkek eşitsizliğinin Türk toplumunun temel bir sorunu olduğunu ifade ederken bu eşitsizliğin nedeni olarak toplumsal yapıyı sorumlu tutması toplumsal cinsiyet kavramı hakkında bilgi düzeylerini de ortaya koymaktadır. Toplumun birçok kesiminin aksine öğrenciler toplumsal cinsiyet hakkında oldukça donanımlı durumdadırlar. Toplumsal cinsiyet ayrımcılığı yaşayan öğrencilerin yaşamayanlara göre daha eşitlikçi bakış açısına sahip olduğu bulunmuştur.

\footnotetext{
* Dr. Öğr. Üyesi, Sivas Cumhuriyet Üniversitesi, Sağlık Bilimleri Fakültesi, Sağlık Yönetimi Bölümü, Email: ydasli@cumhuriyet.edu.tr Orcid No: 0000-0001-6569-1113.
}

Gönderim:15.12.2018 Kabul:11.02.2019 Kayın:15.03.2019


Anahtar sözcükler: Toplumsal cinsiyet, toplumsal cinsiyet rolleri, toplumsal cinsiyet tutumu, öğrenciler.

\section{A Field Study on Determining the Attitudes of Students on Gender Roles}

Abstract: The aim of the study is to determine the gender role attitudes of students and the factors affecting them. The research was conducted in Sivas Cumhuriyet University Faculty of Education. As the population number of the study was known, a sample account was made and 350 people were included in the study. The data of the study were collected by using Personal Information Form and Gender Role Attitude Scale (TCRQ). The data were evaluated in SPSS 22 program. $73.7 \%$ of the students stated that women and men do not have equal rights in Turkish society, $65.4 \%$ said that the reason of the inequality is social structure and $39.7 \%$ of them stated that they experienced gender discrimination. The mean total score of the female students was found to be statistically higher than the male students $(\mathrm{p}<0.05)$. There was no statistically significant difference in gender roles sub-dimension as their mothers' education level ( $\mathrm{p}>0.05$ ). On the other hand, according to the educational status of the father, the role of gender equality, female gender role, traditional gender role and male gender roles are the subdimensions, and there was a statistically significant difference between the sub-dimension mean scores $(\mathrm{p}<0.05)$. It was found that the students taking part in the study have a generally egalitarian gender role. On the other hand, it has been found that female students have higher egalitarian gender roles and attitudes than male students. Three-quarters of the participants stated that inequality between women and men is a fundamental problem of Turkish society, and their commitment to social structure as the cause of this inequality also reveals their level of knowledge about the concept of gender. In contrast to many sections of the society, students are well-equipped about gender. It has been found that students who have gender discrimination have a more egalitarian perspective than those who do not.

Key words: Gender, gender roles, gender attitudes, students.

\section{Giriş}

Cinsiyet (sex) terimi, kadın ve erkek olmanın biyolojik yönünü ifade etmektedir ve biyolojik bir yapıya karşı1ık gelmektedir. Cinsiyet, bireyin biyolojik cinsiyeti bağlamında belirlenen demografik bir kategoridir. Bireylerin kimlik kartlarında yazan cinsiyet bu terim anlamına uygundur (Bayhan, 2013: 153). Toplumsal cinsiyet kavramı ise kadın ve erkek 
olmaya toplumun ve kültürün atfettiği anlamları ve beklentileri ifade etmektedir. Toplumsal cinsiyet, kültürel değerlere, zamana ve yere göre değişiklik göstermektedir (Outhwaite, 2003: 252). Toplumsal cinsiyet kavramını sosyolojiye kazandıran sosyolog Ann Oakley’e göre “cinsiyet biyolojik kadın erkek ayrımını anlatırken, toplumsal cinsiyet (gender) erkeklik ile kadınlık arasındaki buna paralel ve toplumsal bakımdan eşitsiz bölünmeye gönderme yapmaktadır” (Marshall, 1999: 98). Toplumsal cinsiyet her bir cinsiyet üyesi için, uygun diye görülen davranış hakkındaki toplumsal beklentilerdir. Toplumsal cinsiyet, erkek ve kadınların birbirinden farklı olmasına yol açan fiziksel niteliklere değil, erkek ve kadın hakkındaki toplum tarafindan oluşturulmuş özelliklere gönderme yapmaktadır (Giddens, 2000: 621). “Toplumsal cinsiyet, kadınlar ve erkeklere ilişkin uygun rollerin tamamen toplumsal olarak üretildiğini ifade eden 'kültürel inşalar'a işaret etmenin bir yoludur. Toplumsal cinsiyet erkeklerin ve kadınların öznel kimliklerinin sadece toplumsal kökenlerini belirgin kılmanın bir yoludur. ...Toplumsal cinsiyet, cinsiyeti olan bir bedene zorla kabul ettirilmiş bir toplumsal kategoridir" (Scott, 2007: 11).

Sosyolog Jo Paoletti'ye göre, on dokuzuncu yüzyılın sonuna kadar beş yaşındaki çocuklara bile üç aşağı beş yukarı üniseks beyaz kıyafetler giydiriliyordu. Küçük çocukların kıyafetlerinin renkli kumaşlarla dikilmesi, toplumsal cinsiyeti günümüzde pembe ve mavi olarak damgalamamızın başlangıcını temsil eder. Fakat kuralların yerine oturması yaklaşık yarım yüz yılı almıştır. Pembe bir süreliğine erkeklere yakıştırılırdı. Çünkü özellik olarak kararlılığı ve güçlülüğü sembolize eden bir renkti ve kırmızının da yakın akrabasıydı ve hırs ve cesareti simgeliyordu. Daha 'ince ve zarif' olan 'inanç ve sebat sembolü' mavi kızlara ayrılmıştı. Ancak yirminci yüzyılın ortalarına doğru mevcut pratikler mavi rengin erkeklere pembe rengin kızlara daha uygun olacağını müjdeliyordu. Erkekler ve kızlar için renk kodlaması açıkça küçük çocukların toplumsal cinsiyet rollerini öğrenmesine yardım etmiştir (Fine, 2001: 220-222). Renkten, giyim tarz ve biçimlerinden modaya kadar bütün sembolik alanlarda toplumsal cinsiyet örüntüsü, toplum tarafından yaratılan ve kodlanan, öğrenilmiş davranış pratiğidir (Bayhan, 2013: 156).

Toplumsal cinsiyet kavramı, cinsiyet eşitsizliğini de beraberinde getirmektedir. Toplumsal cinsiyet eşitliğini sağlama yönünde hem ülkelerin yerel kurum ve kuruluşları hem de uluslararası kuruluşlar aracılığıyla birçok çalışma yapılmasına karşın cinsiyet eşitliğinin sağlandığını söylemenin olanağı yoktur. Cinsiyete dayalı eşitlik konusu farklı kesimler tarafından farklı bir biçimde anlaşılmaktadır. Durum öylesine farklı boyutlara taşınmaktaki 
hatta "erkeklerin yaptığı işi kadınlar da yapsın söylemi doğmaktadır”. Bu nedenle eşitlikten kasıt biyolojik farklılıkları da gözeterek niteliksel anlamda bir eşitliğin sağlanmasıdır. Yani hak, sorumluluk ve firsatlara erişim bakımından kadın ve erkek arasında bir farklılığın bulunmaması anlaşılmalıdır. Cinsiyete dayalı eşitsizliğin ortadan kalkabilmesi için öncelikli olarak toplumsal cinsiyet eşitliğinden ne anlaşılması gerektiğinin ortaya konulması gerekmektedir. Yapılan araştırmalar, toplumsal cinsiyet eşitsizliği ile erkekliğin ve erkeklerin toplumsal cinsiyet kimliklerinin toplumsal tanımlarının beraber ürettiğini ortaya koymaktadır. $\mathrm{Bu}$ yüzden toplumsal cinsiyet eşitliğine dayalı bir toplum oluşturmak erkeklerin tekrar düşünmelerini, geleneksel erkeklik kimliklerini gözden geçirmelerini, yeni davranış biçimleri geliştirmelerini ve kadınlarla olan ilişkilerini yeniden şekillendirmelerini gerekli kılar (Connell, 2004: 7-9). Dolayısıyla toplumsal cinsiyet eşitliği erkeklerin değişimini ve erkeklerin katılımını da içerir.

Toplumsal cinsiyet roller ve tutumlarının ortaya çıkarılması amacıyla farklı kesimler üzerine birçok çalışma yapılmaktadır. Toplumların tarihsel süreci içinde, toplumsal cinsiyet algıları sürekli bir biçimde değişen dinamik bir kavram olup zamana, mekâna, sınıfa ya da ırka göre olduğu gibi toplumun siyasi, ekonomik, sosyal ve kültürel yapısına göre de çeşitlilik göstermektedir. Ulusal ve uluslararası literatürde, orta öğretim ve üniversite öğrencilerinin toplumsal cinsiyet rollerine ilişkin algılarını belirlemek amacıyla çok sayıda araştırma yapılmıştır (Atış, 2010; Baykal, 1988; Keith ve Jacqueline, 2002; Kimberly ve Mahaffy, 2002; Öngen ve Aytaç, 2013; Seçgin ve Tural, 2011; Vefikuluçay, Demirel, Taşkın ve Eroğlu, 2007; Yılmaz, Zeyneloğlu, Kocaöz, Kısa, Taşkın ve Eroğlu, 2009; Zeyneloğlu, 2008). Literatürde (Keith ve Jacqueline, 2002; Kimberly ve Mahaffy, 2002) üniversite öğrencilerinin toplumsal cinsiyet rollerine ilişkin geleneksel ve geleneksel olmayan algılarını belirlemek amacıyla yapılan çalışmalarda; öğrencilere "kadının temel görevi eve ve aileye bakmaktır", "evin reisi erkek olmalıdır”, “ailenin geçimini sağlamak erkeğin sorumluluğunda olmalıdır” vb. gibi toplumsal cinsiyet rollerini içeren ifadeler yöneltilmiştir. Araştırmaların sonucunda öğrencilerin cinsiyet rolleri konusunda geleneksel rolleri benimsedikleri belirlenmiştir.

Toplumsal cinsiyet, farklı kültürde, tarihin farklı anlarında ve farklı coğrafyalarda kadınlara ve erkeklere toplumsal olarak yüklenen roller ve sorumlulukları ifade eder. Toplumsal cinsiyet kısaca, sosyal yönden kadın ve erkeğe verilen roller, sorumluluklar olarak tanımlanır. Hepimiz dünyaya kız ya da erkek olarak geliriz. Bu bizim seçtiğimiz bir şey değildir. Hangi kültürde veya hangi çağda yaşarsak yaşayalım, kız ya da erkek olarak doğmak, 
tıpkı ölümlü olmak gibi biyolojik varlığımızın bir niteliğidir. Ancak daha doğum öncesinde kız bebeklerin eşyaları için pembe, erkek bebeklerin eşyaları için mavi rengin tercih edilmesiyle başlayan süreç, erkeklerin ve kadınların yapabileceği işler konusunda da yapay ayrımlar üretir. Toplumsal cinsiyet rolleri, "kadınlığın ve erkekliğin sosyal ortamlarda ifade edilişidir ve kültürel beklentileri de ifade eder. Bir erkek için uygun olduğu düşünülen davranışlar erkeksi, kadınlar için uygun olduğu düşünülen davranışlar ise kadınsı olarak adlandırılır. Bu kadınsı ve erkeksi rollerin, cinsiyetten bağımsız olarak ifade edildiği gibi bireylerin bulundukları ortama göre değiştiği gözlenebilmektedir” (Dökmen, 2004: 18).

Toplumsal cinsiyeti ortaya çıkaran birçok faktör bulunmaktadır. Bu faktörler içerisinde en önemli olanları aile, devlet, sokak, medya ve eğitimdir. Toplumsal yapıda, egemen kültürün bir parçası olan toplumsal cinsiyet rolleri, başta aile olmak üzere toplumun diğer kurumlarınca bireye aktarılır, öğrenilen ve içselleştirilen cinsiyet rollerini ortaya çıkartır. Kız ve erkek çocuklara farklı davranılır ve bu farklı davranışlar sonucu kız ve erkek çocuklar kendilerine sunulan rolleri oynamayı öğrenir. Daha doğar doğmaz, çocuklara verilen isimlerden, giydirilen elbiselere, odalarının dekorundan, alınan oyuncaklara nasıl bir kız ya da nasıl bir erkek olacağı aile içerisinde öğretilmeye başlanır. Aile doğan erkek çocuğunu "nazlı oğlum" diye sevmezken aynı biçimde kız çocuğunu da "aslan kızım” diye sevmemektedir.

\section{Araştırmanın Metodolojisi}

Tanımlayıcı ve kesitsel tipte olan bu araştırma, 01-31 Ekim 2018 tarihleri arasında Sivas Cumhuriyet Üniversitesi Eğitim Fakültesinde öğrenim gören öğrencilere yapılmıştır. Araştırmanın evrenini eğitim fakültesinde öğrenim görmekte olan 3.087 öğrenci oluşturmaktadır. Araştırma örneklemine girecek öğrenci sayısı; $n=N . t^{2} . p . q / d^{2}(N-1)+t^{2}$.p.q formülü ile hesaplanmıştır $(p=0.50 . q=0.50 . d=0.05 . t=1.96)$. Araştırmanın örnekleminde evren sayısı bilindiği için örneklem hesabı yapılmış ve 350 kişi olarak bulunmuştur. Cinsiyet araştırma açısından hayati öneme sahip olduğundan tabakalı örneklem yöntemi kullanılmış ve 176 kadın 174 erkek öğrenci örnekleme alınarak basit-rastgele örneklem yöntemi kullanılarak araştırma uygulanmıştır. Araştırmada veri toplama aracı olarak kullanılan anket formunda iki bölüm bulunmakta, birinci bölüm demografik soruların yer aldığı Kişisel Bilgi Formu ve ikinci bölüm Zeyneloğlu (2008) tarafindan geliştirilen Toplumsal Cinsiyet Rolleri Tutum Ölçeği (TCRTÖ)'nden oluşmaktadır.

TCRTÖ üniversite öğrenimi gören öğrencilerin toplumsal cinsiyet rollerine ilişkin tutumlarını belirlemek amacıyla Zeyneloğlu (2008) tarafından geliştirilmiştir. Toplam 38 
maddeden oluşan TCRTÖ 38 madde ve 5 alt boyuttan oluşmuştur. Alt boyutları sırasıyla eşitlikçi cinsiyet rolü, kadın cinsiyet rolü, evlilikte cinsiyet rolü, geleneksel cinsiyet rolü ve erkek cinsiyet rolüdür. Ölçek 5'li likert tipli bir ölçektir. En yüksek puan 190'dır ve ölçekten elde edilen en yüksek değer bireyin toplumsal cinsiyet rollerine ilişkin eşitlikçi tutuma sahip olduğunu gösterir. En düşük değer ise 38 olarak hesaplanır ve bireyin toplumsal cinsiyet rollerine ilişkin geleneksel tutuma sahip olduğunu ifade eder. Ölçeğin Cronbach alfa güvenirlik katsayısı 0.91 olarak bulunmuştur (Zeyneloğlu ve Terzioğlu, 2011). Bu araştırmada Cronbach alfa değeri 0.91 ve yüksek güvenilirliğe sahip olduğu bulunmuştur.

$\mathrm{Bu}$ araştırma için Etik Kurul onayı alındıktan sonra araştırma öncesi ilgili kurumdan yazılı izin alınmıştır. Çalışmaya başlamadan önce gönüllülük esası alınarak yalnızca çalışmaya katılmayı kabul eden öğrencilerin alınacağı, alınan bilgilerin sadece araştırma için kullanılacağı, bireysel bilgilerin araştırmacı ile paylaşıldıktan sonra korunacağı, araştırmanın amacı, süresi konusunda açıklama yapılarak yazılı ve sözlü onam alınmıştır.

Veriler bilgisayar ortamında SPSS (Statistical Package For Social Sciences) 22.0 programında değerlendirilmiştir. Öğrencilerin bireysel özellikleri sayı ve yüzde olarak ifade edilmiştir. TCRTÖ puanı ortalama standart sapma olarak gösterilmiştir. Normal dağılıma uygunluğu Kolmogorov Smirnov testi ile değerlendirilmiştir. TCRTÖ ve alt boyutları toplam puanlarının ise normal dağılıma uygun olmadığı belirlenmiştir $(p<0.05)$. Öğrencilerin özelliklerine göre TCRTÖ ölçeği puan ortalamasının karşılaştırılmasında ikili gruplarda; parametrik test varsayımları yerine getirilmediğinden ikili gruplarda Mann-Whitney U testi, üçlü ve daha çok gruplarda Kruskall-Wallis H testi kullanılmış ve istatistiksel anlamlılık düzeyi için $\mathrm{p}<0.05$ alınmıştır. Kadın Erkek Eşitsizliğinin Nedeni ile Cinsiyet Değişkeninin Karşılaştırılması için Ki-Kare testinden yararlanılmıştır.

\section{Araştırmanın Bulguları}

Araştırmaya katılan öğrencilerin sosyo-demografik özellikleri tablo 1'de gösterilmektedir. Çalışmaya katılan öğrencilerin 176 (\% 50,3) kişisi kadınlardan, 174 (\% 49,7) kişisi ise erkeklerden oluşmaktadır. Katılımcıların büyük bir çoğunluğunu $(\% 72,8)$ ikinci ve üçüncü sınıf öğrencileri oluştururken, 28 kişisini birinci sınıf ve 67 kişisi ise dördüncü sınıf öğrencilerinden oluşmaktadır. Toplumsal cinsiyet rol tutumlarının oluşmasında önemli bir role sahip olan aile biçimlerinde bakıldığında çalışma kapsamında yer alan öğrencilerin \% 72,5’i çekirdek aile tipinde yaşamaktadır. Geniş aile içerisinde yaşayan öğrencilerin oranı yalnızca \% 23,8’dir. Anne-baba eğitim durumu da öğrencilerin toplumsal cinsiyet rollerini benimsemesi 
üzerinde etkili olabilmektedir. Buna göre katılımcıların annelerinin eğitim düzeyinin oldukça düşük olduğu göze çarpmaktadır. Aynı şekilde baba eğitim durumu da oldukça düşük düzeydedir. Her iki ebeveynde de üniversite mezunu olanların oranı oldukça düşük olup genel olarak yığılma ilkokul ve ortaokul düzeyindedir.

Tablo 1: Katılımcıların Sosyo-Demografik Özellikleri

\begin{tabular}{|c|c|c|}
\hline Cinsiyet & Sayı & Yüzde(\%) \\
\hline Kadın & 176 & 50,3 \\
\hline Erkek & 174 & 49,7 \\
\hline Toplam & 350 & 100,0 \\
\hline Sinif & Sayı & Yüzde(\%) \\
\hline Birinci Sınıf & 28 & 8,0 \\
\hline İkinci Sınıf & 146 & 41,7 \\
\hline ÜÇüncü Sinıf & 109 & 31,1 \\
\hline Dördüncü Sınıf & 67 & 19,1 \\
\hline Toplam & 350 & 100,0 \\
\hline Aile Tipi & Sayı & Yüzde(\%) \\
\hline Geniş Aile & 83 & 23,8 \\
\hline Eksik/Parçalanmış Aile & 13 & 3,7 \\
\hline Çekirdek Aile & 253 & 72,5 \\
\hline Toplam & 349 & 100,0 \\
\hline Anne Eğitim Durumu & Sayı & Yüzde(\%) \\
\hline Okur-Yazar Değil & 44 & 12,6 \\
\hline Okur-Yazar & 64 & 18,3 \\
\hline İlkokul & 96 & 27,4 \\
\hline Ortaokul & 95 & 27,1 \\
\hline Lise & 37 & 10,6 \\
\hline Üniversite & 14 & 4,0 \\
\hline Toplam & 350 & 100,0 \\
\hline Baba Eğitim Durumu & Sayı & Yüzde(\%) \\
\hline Okur-Yazar Değil & 9 & 2,6 \\
\hline Okur-Yazar & 47 & 13,5 \\
\hline İlkokul & 75 & 21,6 \\
\hline Ortaokul & 104 & 29,9 \\
\hline Lise & 87 & 25,0 \\
\hline Üniversite & 26 & 7,5 \\
\hline Toplam & 348 & 100,0 \\
\hline
\end{tabular}

Tablo 2'de katılımcıların kadın-erkek eşitliğine ilişkin tutumları ve cinsiyet ayrımcılığına uğrayıp uğramadıklarına ilişkin ifadelerinin dağılımı yer almaktadır. Buna göre katılımcıların büyük bir çoğunluğu $(\% 73,7)$ Türk toplumunda kadınla erkek arasında eşitsizlik olduğunu ifade etmektedir. Araştırma bulguları arasında dikkat çeken bir hususta kadın-erkek arasında eşitlik olmadığını ifade eden 286 kişiden 187'sinin (\% 65,4) eşitsizliğin nedeni olarak 
“toplum yapısı"nı görmüş olmalarıdır. Eşitsizlik nedeni olarak "biyolojik farklılık”ları ifade edenlerin oranı ise \% 5,9'dur. Bu bulgulara göre öğrencilerin büyük bir çoğunluğu toplumsal cinsiyetin mevcut toplumsal yapıdaki egemen olan normlardan, değerlerden, örf adetlerden gelenek ve göreneklerden kısacası kültürden kaynaklı olduğunu ifade etmektedir. Bulgular açıkça eğitimle toplumsal cinsiyet arasındaki ilişkiye vurgu yapmaktadır. Çalışmaya katılan öğrencilerin yaklaşık olarak \% 40’1 cinsiyetinden kaynaklı olarak ayrımcılığa maruz kalırken, $\% 41,4$ 'ü ise ayrımcılık yaşamamıştır.

Tablo 2: Katılımcıların Kadın Erkek Eşitliğine İlişkin Düşünceleri

\begin{tabular}{lcc}
\hline $\begin{array}{l}\text { Türkiye Toplumunda Şu Anda Kadın } \\
\text { ve Erkek Eşit Midir? }\end{array}$ & Sayı & Yüzde(\%) \\
\hline Eşittir & 40 & 11,4 \\
\hline Kararsızım & 52 & 14,9 \\
\hline Eşit Değildir & 258 & 73,7 \\
\hline Toplam & 350 & 100,0 \\
\hline $\begin{array}{l}\text { Cevabınız “Eşit Değildir” İse Size } \\
\text { Göre Eşitsizliğin En Önemli Nedeni } \\
\text { Nedir? }\end{array}$ & Sayı & Yüzde(\%) \\
\hline Biyolojik Farklılık & 17 & 5,9 \\
\hline Aile & 4 & 1,4 \\
\hline Eğitimsizlik & 69 & 24,1 \\
\hline Toplum Yapısı & 187 & 65,4 \\
\hline Ekonomik & 8 & 2,8 \\
\hline Siyasi & 1 &, 3 \\
\hline Toplam & 286 & 100,0 \\
\hline $\begin{array}{l}\text { Cinsiyetinizden Kaynaklı Olarak } \\
\text { Bugüne Kadar Hiç Ayrımcılı̆̆a }\end{array}$ & & Yüzde(\%) \\
Uğradınız Mı? & Sayı & 39,7 \\
\hline Uğradım & & 19,0 \\
\hline Hatırlamıyorum & 138 & 41,4 \\
\hline Uğramadım & 66 & 100,0 \\
\hline Toplam & 144 &
\end{tabular}

Yapılan normal dağılım analizi sonucu tablo 3'de görülmekte olup buna göre, ölçeklerin normal dağılımdan gelmediği tespit edilmiştir $(\mathrm{p}<0,05)$. Analizlere non-parametrik testlerle devam edilmiştir.

Tablo 3: Ölçeğin Normal Dağılım Testi Sonuçları

\begin{tabular}{lcccccc}
\hline & \multicolumn{2}{c}{ Kolmogorov-Smirnov } & \multicolumn{3}{c}{ Shapiro-Wilk } \\
Toplumsal Cinsiyet rolleri & Statistic & df & Sig. & Statistic & df & Sig. \\
\hline Eşitlikçi Cinsiyet Rolü &, 142 & 286 &, 000 &, 895 & 286 &, 000 \\
\hline Kadın Cinsiyet Rolü &, 105 & 286 &, 000 &, 973 & 286 &, 000 \\
\hline Evlilikte Cinsiyet Rolü &, 145 & 286 &, 000 &, 882 & 286 &, 000 \\
\hline Geleneksel Cinsiyet Rolü &, 065 & 286 &, 005 &, 975 & 286 &, 000 \\
\hline Erkek Cinsiyet Rolü &, 135 & 286 &, 000 &, 914 & 286 &, 000 \\
\hline Genel Ölçek &, 065 & 284 &, 005 &, 975 &, 284 &, 000 \\
\hline
\end{tabular}


TCRTÖ’nün Cronbach Alfa Güvenirlik Katsayısı 38 madde için Cronbach's Alpha değeri 0,914 olarak bulunmuştur. $\mathrm{Bu}$ değer ölçeğin güvenilirliğinin, $0,80<$ Cronbach’s Alpha $<1,00$ arasında olduğundan, çok yükssek düzeyde olduğunu gösterir. Bu sonuç, ölçek maddelerinin birbiriyle yüksek iç tutarlılığa ve yüksek güvenirliğe sahip olduğunu göstermektedir. Alt boyutlara ilişkin Cronbach Alfa Güvenirlik Katsayıları tablo 4'de yer almaktadır. Eşitlikçi Cinsiyet Rolü, Kadın Cinsiyet Rolü, Evlilikte Cinsiyet Rolü, Geleneksel Cinsiyet Rolü ve Erkek Cinsiyet Rolü alt boyutlarının Cronbach Alfa Güvenirlik Katsayıları sirasılya “ $0,778,0,730,0,731,0,797$ ve 0,724 'dür. Bu analizler ölçeğin beş alt boyutunun da güvenilir olduğunu ortaya koymaktadır.

Tablo 4: Güvenilirlik Analizi

\begin{tabular}{lcc}
\hline & Cronbach’s Alpha & Madde Sayıs1 \\
Eşitlikçi Cinsiyet Rolü &, 778 & 8 \\
\hline Kadın Cinsiyet Rolü &, 730 & 8 \\
\hline Evlilikte Cinsiyet Rolü &, 731 & 8 \\
\hline Geleneksel Cinsiyet Rolü &, 797 & 8 \\
\hline Erkek Cinsiyet Rolü &, 724 & 6 \\
\hline Toplumsal Cinsiyet Rolleri &, 914 & 38 \\
\hline
\end{tabular}

Tablo 5’de toplumsal cinsiyet rolü ölçeği ve alt boyutları için tanımlayıcı istatistik sonuçları verilmiştir. Öğrencilerin TCRTÖ’den alabilecekleri maksimum puan 190 olup, bu değer öğrencinin cinsiyet rollerine ilişkin eşitlikçi tutuma sahip olduğunu göstermektedir. Tersi biçimde alınacak en düşük puan 38 olup, bu ise öğrencinin toplumsal cinsiyet rollerine ilişkin geleneksel tutuma sahip olduğunu göstermektedir. Bu çalışmada toplumsal cinsiyet rolü ölçeği genelinden alınabilecek puan ortalamaları 148,82 $\pm 22,47$ 'dir. Araştırmada elde edilen bu sonuç, öğrencilerin toplumsal cinsiyet rollerine ilişkin eşitlikçi tutuma sahip olduklarını göstermektedir. Eşitlikçi cinsiyet rolü alt boyutu puanı 33,63 $\pm 5,83$, kadın cinsiyet rolü $27,62 \pm 6,29$, evlilik cinsiyet rolü alt boyutu ortalama puanı $34,87 \pm 4,84$, geleneksel cinsiyet rolü alt boyutu ortalama puanı $28,08 \pm 6,70$, erkek cinsiyet rolü alt boyutu ortalama puanı $24,40 \pm 4,54$ olarak belirlenmiştir.

Tablo 5: Katılımcıların Toplumsal Cinsiyet Rolleri Ölçeğine Ait Betimleyici İstatistikler

\begin{tabular}{lcc}
\hline & $\bar{X}$ & S.s. \\
\hline Eşitlikçi Cinsiyet Rolü & 33,63 & 5,83 \\
\hline Kadın Cinsiyet Rolü & 27,62 & 6,29 \\
\hline Evlilikte Cinsiyet Rolü & 34,87 & 4,84 \\
\hline Geleneksel Cinsiyet Rolü & 28,08 & 6,70 \\
\hline Erkek Cinsiyet Rolü & 24,40 & 4,54 \\
\hline Toplumsal Cinsiyet Rolleri & 148,82 & 22,47 \\
\hline
\end{tabular}


Araştırmaya katılan katılımcıların toplumsal cinsiyet rolleri ve alt boyutlarına ait algıların demografik değişkenlere göre farklılığın istatistiksel olarak anlamlı olup olmamasını test etmek için yapılan Mann-Whitney U ve Kruskal-Wallis $H$ testi sonuçları tablo 6'da görülmektedir. Tablo 6’ya göre, eşitlikçi cinsiyet rolü alt boyut algılarının cinsiyete göre farklılı̆̆ istatistiksel olarak \% 95 güven seviyesinde anlamlı olduğu $(U=10601,5 ; p<0,05)$ belirlenmiştir. Kadınların (Mean Rank=202,26) eşitlikçi cinsiyet rolleri algıları erkeklere (Mean Rank=148,43) göre daha yüksektir. Kadın cinsiyet rolü alt boyut algılarının cinsiyete göre farklılığg istatistiksel olarak \% 95 güven seviyesinde anlamlı olduğu $(U=6962,0 ; p<0,05)$ belirlenmiştir. Kadınların (Mean Rank=201,76) erkeklere nazaran daha eşitlikçi kadın cinsiyet rolüne sahip olduğu görülmektedir. Tablo 6'daki bulgular tüm alt boyutlarda kadınların erkeklere oranla daha eşitlikçi toplumsal cinsiyet rol tutumuna sahip olduğunu göstermektedir. Eksik parçalanmış aile tipine sahip olan katılımcıların eşitlikçi (Mean Rank=245,08) ve kadın cinsiyet rolü (Mean Rank=220,15) algıları daha yüksektir. Baba eğitim durumu okur-yazar olmayan öğrencilerin evlilikte cinsiyet rolü (Mean Rank=73,06) algıları daha düşüktür. Tablo 6'da görüleceği üzere anne eğitim durumu toplumsal cinsiyet rolleri alt boyutlarında istatistiksel olarak anlamlı farklılık göstermemektedir. 
Tablo 6: Katılımcıların Toplumsal Cinsiyet Rolleri Ölçeği Alt Boyutlarına İlişkin Görüşlerinin Demografik Değişkenlerine Göre Farklılıklarına Ait Analiz Sonuçları

TCRTÖ Alt Boyut ve Toplum Puan Ortalaması

\begin{tabular}{|c|c|c|c|c|c|c|}
\hline Değişkenler & $\begin{array}{c}\text { Eşitlikçi } \\
\text { Cinsiyet } \\
\text { Rolü } \\
\end{array}$ & $\begin{array}{c}\text { Kadın } \\
\text { Cinsiyet } \\
\text { Rolü } \\
\end{array}$ & $\begin{array}{c}\text { Evlilikte } \\
\text { Cinsiyet } \\
\text { Rolü } \\
\end{array}$ & $\begin{array}{c}\text { Geleneksel } \\
\text { Cinsiyet } \\
\text { Rolü } \\
\end{array}$ & $\begin{array}{c}\text { Erkek } \\
\text { Cinsiyet } \\
\text { Rolü } \\
\end{array}$ & Toplum \\
\hline & Mean Rank & $\begin{array}{l}\text { Mean } \\
\text { Rank }\end{array}$ & $\begin{array}{l}\text { Mean } \\
\text { Rank }\end{array}$ & Mean Rank & $\begin{array}{l}\text { Mean } \\
\text { Rank }\end{array}$ & $\begin{array}{l}\text { Mean } \\
\text { Rank }\end{array}$ \\
\hline \multicolumn{7}{|l|}{ Cinsiyet } \\
\hline Kadın & 202,26 & 201,76 & 201,76 & 205,54 & 194,48 & 183,33 \\
\hline Erkek & 148,43 & 124,95 & 122,69 & 116,31 & 135,56 & 102,81 \\
\hline İstatistiksel Analiz & $\begin{array}{c}\mathrm{U}=10601,5 ; \\
\mathrm{p}=, 000^{*}\end{array}$ & $\begin{array}{c}\mathrm{U}=6962,0 ; \\
\mathrm{p}=, 000^{*}\end{array}$ & $\begin{array}{c}\mathrm{U}=6712,0 ; \\
\mathrm{p}=, 000^{*}\end{array}$ & $\begin{array}{c}\mathrm{U}=5729,5 ; \\
\mathrm{p}=, 000^{*}\end{array}$ & $\begin{array}{c}\mathrm{U}=8809,5 ; \\
\mathrm{p}=, 000^{*}\end{array}$ & $\begin{array}{c}\mathrm{U}=4364,5 ; \\
\mathrm{p}=, 000^{*}\end{array}$ \\
\hline \multicolumn{7}{|l|}{ Aile Tipi } \\
\hline Geniş Aile & 143,19 & 148,19 & 146,55 & 161,96 & 168,62 & 128,77 \\
\hline $\begin{array}{c}\text { Eksik/Parçalanmış } \\
\text { Aile } \\
\end{array}$ & 245,08 & 220,15 & 195,71 & 183,54 & 169,00 & 179,92 \\
\hline Çekirdek Aile & 181,83 & 163,61 & 168,53 & 156,73 & 164,29 & 143,40 \\
\hline İstatistiksel Analiz & $\begin{array}{c}\chi^{2}=15,799 \\
\mathrm{p}=, 000^{*}\end{array}$ & $\begin{array}{c}\chi^{2}=6,632 ; \\
\mathrm{p}=, 036 *\end{array}$ & $\begin{array}{c}\chi^{2}=4,464 ; \\
p=, 107\end{array}$ & $\begin{array}{c}\chi^{2}=1,152 ; \\
p=, 562\end{array}$ & $\begin{array}{c}\chi^{2}=0,140 ; \\
p=, 932\end{array}$ & $\begin{array}{c}\chi^{2}=4,129 \\
p=, 127\end{array}$ \\
\hline \multicolumn{7}{|l|}{$\begin{array}{c}\text { Anne Eğitim } \\
\text { Durumu }\end{array}$} \\
\hline Okur-yazar değil & 174,47 & 154,57 & 159,33 & 145,14 & 169,33 & 130,18 \\
\hline Okur-yazar & 174,79 & 145,08 & 154,03 & 170,94 & 168,84 & 140,21 \\
\hline İlkokul & 187,90 & 155,57 & 171,35 & 153,43 & 171,06 & 146,21 \\
\hline Ortaokul & 170,16 & 178,25 & 170,39 & 160,56 & 163,21 & 147,39 \\
\hline Lise & 150,54 & 166,86 & 158,44 & 167,74 & 154,32 & 131,10 \\
\hline Üniversite & 199,21 & 204,61 & 172,36 & 161,50 & 155,04 & 159,25 \\
\hline İstatistiksel Analiz & $\begin{array}{c}\chi^{2}=4,769 ; \\
p=, 445\end{array}$ & $\begin{array}{c}\chi^{2}=8,176 ; \\
p=, 147\end{array}$ & $\begin{array}{c}\chi^{2}=1,900 ; \\
p=, 863\end{array}$ & $\begin{array}{c}\chi^{2}=2,435 \\
p=, 786\end{array}$ & $\begin{array}{c}\chi^{2}=1,096 ; \\
p=, 954\end{array}$ & $\begin{array}{c}\chi^{2}=2,324 ; \\
p=, 803\end{array}$ \\
\hline \multicolumn{7}{|l|}{$\begin{array}{c}\text { Baba Eğitim } \\
\text { Durumu }\end{array}$} \\
\hline Okur-yazar değil & 120,39 & 162,83 & 73,06 & 118,56 & 134,50 & 95,19 \\
\hline Okur-yazar & 171,47 & 170,76 & 140,76 & 168,26 & 175,92 & 136,94 \\
\hline İlkokul & 187,33 & 151,39 & 179,85 & 157,33 & 161,59 & 148,88 \\
\hline Ortaokul & 167,46 & 161,80 & 170,04 & 154,49 & 165,86 & 140,31 \\
\hline Lise & 189,33 & 165,94 & 161,46 & 160,82 & 171,15 & 146,04 \\
\hline Üniversite & 140,23 & 167,06 & 172,46 & 168,32 & 144,50 & 132,58 \\
\hline İstatistiksel Analiz & $\begin{array}{c}\chi^{2}=9,349 \\
p=, 096\end{array}$ & $\begin{array}{c}\chi^{2}=1,531 ; \\
p=, 909\end{array}$ & $\begin{array}{c}\chi^{2}=12,708 ; \\
p=, 026^{*}\end{array}$ & $\begin{array}{c}\chi^{2}=2,689 \\
p=, 748\end{array}$ & $\begin{array}{c}\chi^{2}=3,165 \\
p=, 675\end{array}$ & $\begin{array}{c}\chi^{2}=3,754 \\
p=, 585\end{array}$ \\
\hline
\end{tabular}

Araştırmaya katılanların toplumsal cinsiyet rolleri ve alt boyutlarına ait algılarının “Kadın-erkek Eşit Midir?” değişkenine göre farklılığın istatistiksel olarak anlamlı olup olmamasını test etmek için yapılan Kruskal-Wallis H testi sonucu tablo 7’de gösterilmektedir. Buna göre, toplumsal cinsiyet rolü algılarının kadın-erkek eşit olma durumuna göre farklılığ1 istatistiksel olarak \%95 güven seviyesinde anlamlı olduğu belirlenmiştir $\left(\chi^{2}=25,184 ; p<0,05\right)$. Toplumsal cinsiyet rolü boyutunda hangi gruplar arasında algının farklılaştığının belirlenmesi amacıyla yapılan Mann-Whitney U testi sonucuna göre kadın-erkek eşit değildir (Mean Rank=157,27) görüşüne sahip olanların toplumsal cinsiyet rolü algıları kadın-erkek eşittir 
(mean Rank=100,53) ve kadın-erkek eşitliği noktasında kararsız (Mean Rank=103,45) olanlara göre daha yüksektir.

Tablo 7: Katılımcıların Toplumsal Cinsiyet Rolleri Ölçeği Alt Boyutlarına İlişkin Görüşlerinin "Kadın Erkek Eşit midir?” Sorusuna Ait Kruskal-Wallis H Testi Sonuçları

\begin{tabular}{|c|c|c|c|c|c|c|}
\hline & $\begin{array}{l}\text { Kadın Erkek } \\
\text { Eşit midir? }\end{array}$ & $\mathbf{N}$ & Mean Rank & $\chi^{2}$ & $\mathbf{p}$ & Fark \\
\hline \multirow{3}{*}{$\begin{array}{l}\text { Eşitlikçi Cinsiyet } \\
\text { Rolü }\end{array}$} & Eşittir & 40 & 157,80 & \multirow{3}{*}{3,896} & \multirow{3}{*}{,143 } & \multirow{3}{*}{-} \\
\hline & Kararsızım & 52 & 157,61 & & & \\
\hline & Eşit Değildir & 258 & 181,85 & & & \\
\hline \multirow{3}{*}{$\begin{array}{l}\text { Kadın Cinsiyet } \\
\text { Rolü }\end{array}$} & Eşittir $^{(1)}$ & 39 & 114,01 & \multirow{3}{*}{24,204} & \multirow{3}{*}{, $000 *$} & \multirow{3}{*}{$\begin{array}{l}(1-3) \\
(2-3)\end{array}$} \\
\hline & Karars1zım ${ }^{(2)}$ & 44 & 124,36 & & & \\
\hline & Eşit Değildir $^{(3)}$ & 242 & 177,92 & & & \\
\hline \multirow{3}{*}{$\begin{array}{l}\text { Evlilikte Cinsiyet } \\
\text { Rolü }\end{array}$} & Eşittir ${ }^{(1)}$ & 38 & 122,50 & \multirow{3}{*}{25,105} & \multirow{3}{*}{, $000 *$} & \multirow{3}{*}{$\begin{array}{l}(1-3) \\
(2-3)\end{array}$} \\
\hline & Karars1zım $^{(2)}$ & 46 & 118,61 & & & \\
\hline & Eşit Değildir ${ }^{(3)}$ & 245 & 180,30 & & & \\
\hline Geleneksel & Eşittir ${ }^{(1)}$ & 38 & 121,38 & \multirow{3}{*}{17,768} & \multirow{3}{*}{,000* } & \multirow{3}{*}{$\begin{array}{l}(1-3) \\
(2-3)\end{array}$} \\
\hline \multirow[t]{2}{*}{ Cinsiyet Rolü } & Kararsızım $^{(2)}$ & 45 & 124,37 & & & \\
\hline & Eşit Değildir $^{(3)}$ & 235 & 172,39 & & & \\
\hline \multirow{3}{*}{$\begin{array}{l}\text { Erkek Cinsiyet } \\
\text { Rolü }\end{array}$} & Eşittir ${ }^{(1)}$ & 40 & 131,29 & \multirow{3}{*}{14,363} & \multirow{3}{*}{, $001^{*}$} & \multirow{3}{*}{$(1-3)$} \\
\hline & Karars1zim ${ }^{(2)}$ & 47 & 133,52 & & & \\
\hline & Eşit Değildir ${ }^{(3)}$ & 246 & 177,76 & & & \\
\hline \multirow{3}{*}{$\begin{array}{l}\text { Toplumsal } \\
\text { Cinsiyet Rolleri }\end{array}$} & Eşittir (1) & 36 & 100,53 & \multirow{3}{*}{25,184} & \multirow{3}{*}{, $000^{*}$} & \multirow{3}{*}{$\begin{array}{l}(1-3) \\
(2-3)\end{array}$} \\
\hline & Kararsızım $^{(2)}$ & 40 & 103,45 & & & \\
\hline & Eşit Değildir (3) & 208 & 157,27 & & & \\
\hline
\end{tabular}

Araştırmaya katılanların toplumsal cinsiyet rolleri ve alt boyutlarına ait algıların ayrımcılığa uğrama durumuna göre farklılığın istatistiksel olarak anlamlı olup olmamasını test etmek için yapılan Kruskal-Wallis H testi sonucu tablo 8'de verilmiştir. Tablo 8'deki bulgulara göre, toplumsal cinsiyet rolü algılarının ayrımcılığa uğrama durumuna göre farklılığı istatistiksel olarak \%95 güven seviyesinde anlamlı olduğu belirlenmiştir $\left(\chi^{2}=18,155 ; p<0,05\right)$. Toplumsal cinsiyet rolü boyutunda hangi gruplar arasında algının farklılaştığının belirlenmesi amacıyla yapılan Mann- Whitney U testi sonucuna göre ayrımcılığa uğradığını düşünenlerin (Mean Rank=162,84) toplumsal cinsiyet rolü algıları ayrımcılığa uğramayanlara (mean Rank=116,85) göre daha yüksektir. 
Tablo 8: Katılımcıların Toplumsal Cinsiyet Rolleri Ölçeği Alt Boyutlarına İlişkin Görüşlerinin Ayrımcılığa Uğrama Durumuna Ait Kruskal-Wallis H Testi Sonuçları

\begin{tabular}{|c|c|c|c|c|c|c|}
\hline & $\begin{array}{l}\text { Ayrımcılığa } \\
\text { Uğrama Durumu }\end{array}$ & $\mathbf{N}$ & Mean Rank & $\chi^{2}$ & $\mathbf{p}$ & Fark \\
\hline \multirow{3}{*}{$\begin{array}{l}\text { Eşitlikçi } \\
\text { Cinsiyet Rolü }\end{array}$} & Uğradım $^{(1)}$ & 138 & 196,15 & \multirow{3}{*}{14,526} & \multirow{3}{*}{,001* } & \multirow{3}{*}{$(1-3)$} \\
\hline & Hatırlamiyorum ${ }^{(2)}$ & 66 & 180,33 & & & \\
\hline & Uğramadım $^{(3)}$ & 144 & 151,08 & & & \\
\hline \multirow{3}{*}{$\begin{array}{l}\text { Kadın Cinsiyet } \\
\text { Rolü }\end{array}$} & Uğradım $^{(1)}$ & 125 & 191,89 & \multirow{3}{*}{22,214} & \multirow{3}{*}{, $000 *$} & \multirow{3}{*}{$(1-3)$} \\
\hline & Hatırlamiyorum $^{(2)}$ & 65 & 153,79 & & & \\
\hline & Uğramadım $^{(3)}$ & 133 & 137,92 & & & \\
\hline \multirow{3}{*}{$\begin{array}{l}\text { Evlilikte } \\
\text { Cinsiyet Rolü }\end{array}$} & Uğradım ${ }^{(1)}$ & 132 & 177,63 & \multirow{3}{*}{8,497} & \multirow{3}{*}{, $014 *$} & \multirow{3}{*}{$(1-3)$} \\
\hline & Hatırlamiyorum ${ }^{(2)}$ & 64 & 173,69 & & & \\
\hline & Uğramadım $^{(3)}$ & 131 & 145,53 & & & \\
\hline \multirow{3}{*}{$\begin{array}{l}\text { Geleneksel } \\
\text { Cinsiyet Rolü }\end{array}$} & Uğradım ${ }^{(1)}$ & 130 & 180,05 & \multirow{3}{*}{14,465} & \multirow{3}{*}{, $001^{*}$} & \multirow{3}{*}{$(1-3)$} \\
\hline & Hatırlamiyorum (2) & 60 & 157,64 & & & \\
\hline & Uğramadım ${ }^{(3)}$ & 126 & 136,67 & & & \\
\hline \multirow{3}{*}{$\begin{array}{l}\text { Erkek Cinsiyet } \\
\text { Rolü }\end{array}$} & Uğradım $^{(1)}$ & 133 & 181,76 & \multirow{3}{*}{16,393} & \multirow{3}{*}{, $000 *$} & \multirow{3}{*}{$\begin{array}{l}(1-3) \\
(2-3)\end{array}$} \\
\hline & Hatırlamiyorum ${ }^{(2)}$ & 64 & 183,76 & & & \\
\hline & Uğramadım $^{(3)}$ & 134 & 139,35 & & & \\
\hline \multirow{3}{*}{$\begin{array}{l}\text { Toplumsal } \\
\text { Cinsiyet } \\
\text { Rolleri }\end{array}$} & Uğradım ${ }^{(1)}$ & 116 & 162,84 & \multirow{3}{*}{18,155} & \multirow{3}{*}{, $000 *$} & \multirow{3}{*}{$(1-3)$} \\
\hline & Hatırlamiyorum ${ }^{(2)}$ & 56 & 145,71 & & & \\
\hline & Uğramadım $^{(3)}$ & 110 & 116,85 & & & \\
\hline
\end{tabular}

Tablo 9'da kadınların toplumda yaşadığı en önemli soruna ilişkin katılımcıların cinsiyet açısından düşünceleri yer almaktadır. "Kadınların yaşadığı en önemli sorun” kadınlar tarafindan ilk sıralarda şiddet (\% 48,3), çevre baskısı (\% 47,7), kadın-erkek eşitsizliği $(\%$ 34,7) ve sokakta baskı ve taciz (\% 25,6) ifade edilirken, erkekler şiddet (\% 40,8), çevre baskısı (\% $39,7)$, eğitimsizlik $(\% 28,2)$ ve sokakta bask1 ve taciz $(\% 25,6)$ sorunlarından ilk sıralarda ifade etmiştir. Buna göre kadınlarla erkelerin kadınların yaşadığı sorunlara ilişkin bakış açıları hemen hemen benzerlik göstermektedir.

Tablo 9: Kadınların Yaşadığı Sorunlar ile Cinsiyet Değişkeninin Dağılımları

\begin{tabular}{|c|c|c|c|c|c|}
\hline & & \multicolumn{4}{|c|}{ Cinsiyet } \\
\hline & & \multicolumn{2}{|c|}{ Kadın } & \multicolumn{2}{|c|}{ Erkek } \\
\hline & & $\mathrm{n}$ & $\%$ & $\mathrm{n}$ & $\%$ \\
\hline \multirow{9}{*}{$\begin{array}{l}\text { Kadınların } \\
\text { Yaşadığı } \\
\text { Sorunlar }\end{array}$} & Aile bask1sı & 33 & 18,8 & 32 & 18,4 \\
\hline & Çevre baskısı & 84 & 47,7 & 69 & 39,7 \\
\hline & Eğitimsizlik & 43 & 24,4 & 49 & 28,2 \\
\hline & İşsizlik & 23 & 13,1 & 11 & 6,3 \\
\hline & İşyerinde taciz ve baskı & 33 & 18,8 & 23 & 13,2 \\
\hline & Şiddet & 85 & 48,3 & 71 & 40,8 \\
\hline & Kadın erkek eşitsizliği & 61 & 34,7 & 47 & 27,0 \\
\hline & Sokakta baskı ve taciz & 45 & 25,6 & 48 & 27,6 \\
\hline & Diğer & 10 & 5,7 & 2 & 1,1 \\
\hline
\end{tabular}




\section{Tartışma ve Sonuç}

Toplumsal cinsiyet eşitsizliği, ülkemizde ve dünyada farklı boyutlarda yaşanan bir sorundur. $\mathrm{Bu}$ araştırma ile öğrencilerin toplumsal cinsiyet rollerine ilişkin tutumlarının belirlenmesi amaçlanmıştır. Toplumsal cinsiyet rollerinin belirlenmesine yönelik daha önce yapılan çalışmalar genellikle öğrenciler ve diğer meslek gruplarının katılımıyla yapılmıştır. Bu çalışmada kız ve erkek öğrencilerin toplumsal cinsiyet rollerine ilişkin olarak eşitlikçi toplumsal cinsiyet rollerine sahip oldukları fakat kızların, erkeklere nazaran daha eşitlikçi tutum ve rollere sahip oldukları (tablo 5) anlaşılmıştır. Bu çalışmanın orta koyduğu sonucun benzer çalışmalar ile desteklendiği görülmektedir (Aşıl1, 2001; Baykal,1988; Çelebi, 1997; Dikmen ve Maden, 2012; Girginer, 1994; Kalaycı, Hayırsever ve Özcan, 2012; Öngen ve Aytaç, 2013; Özden ve Gölbaş1, 2018; Seçgin ve Tural, 2011; Temel, 1991).

Toplumsal cinsiyette açısından eşitlik denildiğinde, akla ilk olarak niceliksel eşitliğin dışında niteliksel anlamda eşitlik gelmelidir. Kadınlar ile erkeklerin yaradılışları ve doğaları gereği niceliksel anlamda iki kere iki dört eder şeklinde bir eşitliğe sahip olabilmeleri mümkün değildir. O halde niteliksel bir eşitlikten yani firsatları kullanma, kaynakların ayrılması ve kullanımında ve hizmetleri elde etmede bireyin cinsiyeti nedeniyle ayrımcilık yapılmamasından söz edilmelidir (Akın, 2007). Araştırma bulgularından da görüldüğü üzere erkek ve kadın öğrenciler arasında toplumsal cinsiyet rolüne yönelik bir tutum farklılığı bulunmaktadır. Bu çalışma ile ortaya konulan sonuç, Öngen ve Aytaç (2013), Seçgin ve Tural (2011), Vefikuluçay vd. (2007), Yılmaz vd. (2009) tarafından yapılan çalışmalarda da elde edilen sonuçlarla benzerlik göstermektedir.

$\mathrm{Bu}$ çalışmada öğrencilerin yaklaşık olarak dörtte üçü Türk toplumunda toplumsal cinsiyetler arasında eşitsizlik olduğunu ve bu eşitsizliğin genel olarak Türk toplum yapısından kaynaklandığını belirtmişlerdir. Öğrencilerinin toplumsal cinsiyet rolü ölçek ve alt boyut puan ortalamaları alınabilecek maksimum puana göre değerlendirildiğinde toplumsal cinsiyet rollerine ilişkin geleneksel bir tutuma sahip olduğu dikkat çekici bir bulgudur. Literatürde öğrencilerin TCRTÖ ve alt boyutların değerlendirildiği çalışmalara bakıldığında araştırma ile ortaya çıkan sonucun diğer çalışmalar ile desteklendiği görülmektedir. Seçgin ve Tural (2011)'ın öğretmen adayları ile yaptığı çalışmada, Özden ve Gölbaşı (2018)'nın sağlık çalışanlarına yaptığı çalışmada, Çelik Bekleviç (2017)’in ve Seyitoğlu, Güneş ve Gökçe (2015)’nin sağlı bölümünde okuyan öğrencilerde yaptıkları çalışmada katılımcılarının 
eşitlikçi toplumsal cinsiyet rollerini benimsedikleri görülmüştür. Daha objektif sonuçlar elde etmek için geniş gruplarla daha fazla çalışmalar yapılması gerekmektedir.

Türkiye, ataerkil toplum yapısından kaynaklı olarak cinsiyet ayrımcılığını yoğun olarak yaşayan ülkelerden biridir. Araştırmaya katılan katılımcıların hemen hemen yarısı toplumsal cinsiyet ayrımcılığına maruz kalmıştır. Toplumsal cinsiyet ayrımcılığı Türkiye'nin temel toplumsal sorunu olup bu durum uluslararası kuruluşlarının çalışmalarına da yansımıştır. Dünya Ekonomik Forumu'nun yayımladığı Cinsiyet Ayrımcılığı 2015 Raporu dünyadaki kadın-erkek eşitsizliğini çok çarpıcı bir biçimde ortaya koymaktadır. Küresel cinsiyet eşitsizliği raporuna göre Türkiye'nin karnesi çok iyi görünmemektedir. Rapora göre Türkiye cinsiyet eşitsizliği sıralamasında 149 ülke arasında 130. sırada yer almaktadır (World Economıc Forum, 2018: 9). Türkiye'nin eşitsizlik indeksi $0.624^{1}$ olup, Türkiye araştırmaya dâhil edilen 149 ülke içerisinde 130. sıraya yerleştirmektedir. Bu eşitsizlik indeksi eğitim, sağlık, politik katılım ve iş gücüne katılım gibi birçok alt başlıkta değerlendirilmektedir. Dünya Ekonomik Formunun yayınladığı rapordaki veriler tablo 2’deki verileri desteklemektedir.

Toplumsal cinsiyet rollerinin geçmişten günümüze hem kadın hem de erkek tarafından içselleştirilmesi, bunun değişmez kurallar bütünü ve doğal olduğunun kabul edilmesi nedeniyle, bu değişimin kolay olacağını söylemek güçtür. Değişim süreci, hem bireyin iç çatışmasını hem de toplumsal bir takım çatışmaları, tartışmaları beraberinde getirecektir. Ama kadın ve erkeğin toplumda eşit, özgür, mutlu bireyler olarak var olabilmeleri içinde değişim kaçınılmazdır (Bülbül, 2014: 14-15).

Toplumsal cinsiyet rollerinin değişmesini sağlayabilecek dönüşümleri hem kültürel hem de sosyo-ekonomik düzeyde ele almak gereklidir. Her iki düzeyde ciddi değişim dönüşüm gerçekleştirmeden, sadece kadınların var olan toplumsal ilişkiler içerisindeki konumu düzeltmeye çalışarak toplumsal cinsiyet eşitliğinin sağlanabileceğini var saymak mümkün gözükmemektedir (Buğra, 2015: 17). Toplumsal cinsiyet eşitliği, kadınlarla birlikte erkeklerin de dönüşümüne atıfta bulunan uzun soluklu bir dönüşüm anlamını taşır. O halde erkeklerde bir zihniyet değişimi yaşanmadığı sürece, erkekler geleneksel rollerini devam ettirdikçe toplumsal cinsiyet eşitliğinin sağlanabilmesi zor görünmektedir.

\footnotetext{
${ }^{1}$ İndeksin Sıfıra (0) yakın olması cinsiyetler arası eşitsizliğin fazlalığını, indeksin Bire (1) yakın olması ise eşitliğin olduğunu ifade etmektedir.
} 
Sonuç olarak Fine (2010: 107)'nın belirttiği gibi “Erkekler de ebeveyndir ve aslına bakılırsa, erkekler evde eşit olana kadar, kadınlar hiçbir zaman ev dışında eşit olamayacak”tır.

Araştırma sonuçlarından yola çıkılarak aşağıdaki öneriler geliştirilmiştir;

- Toplumsal cinsiyet ile ilgili düzenlenecek sempozyum ve panellerde konunun öğrenciler tarafından tartışılması ve toplum tarafından biçimlendirilmiş geleneksel görüşlerinin farkına varmalarının sağlanması,

- Toplumsal cinsiyet rollerine ilişkin farkındalığın oluşabilmesi için fakülte bölüm ayrımı yapılmadan tüm okullarda toplumsal cinsiyetin ders olarak okutulması,

- Toplumsal cinsiyet rollerinin aile içerisinde edinildiği gerçeğinden hareketle toplumsal cinsiyet konusunda anne-baba eğitimlerinin düzenlenmesi,

- Toplumsal cinsiyet rollerine ilişkin yapılacak olan araştırmaların daha fazla oranda desteklenerek, cinsiyet rolleri konusunda farkındalık yaratacak araştırmalar yapılmasını sağlamak,

\section{Makalenin Bilimdeki Konumu}

Sosyal Bilgiler Eğitimi Anabilim Dalı

\section{Makalenin Bilimdeki Özgünlüğü}

Literatür tarandığında toplumsal cinsiyet rol ve tutumlarının değişik kesimler üzerine özelliklede öğrenciler üzerine yapılan çalışmalarla ortaya konulduğu görülmektedir. Öğretmen adayları üzerine yapılan çalışmaların oldukça sınırlı kapsamda olduğu, sayılarının oldukça az ve bu çalışmaların belirli bölümler üzerine yapıldığı görülmektedir. Toplumsal cinsiyet eşitsizliğinin sağlanabilmesi için gelecek nesilleri yetiştirecek olan öğretmenlere oldukça fazla görev düşmektedir. $\mathrm{Bu}$ gerçeklikten hareketle öncelikle öğretmen adaylarının toplumsal cinsiyet rol ve tutumlarının ne olduğunun ortaya konulması gerekmektedir. Çalışmanın evrenine giren Sivas Cumhuriyet Üniversitesi Eğitim Fakültesi öğrencileri üzerine yapılan bu çalışma ilk olma özelliğine sahiptir. Bu çalışmanın özgünlüğü genelde öğretmen adayları üzerine özelde ise Sivas Cumhuriyet Üniversitesi Eğitim Fakültesi öğrencileri üzerine yapılmış olmasidir.

\section{Kaynakça}

Aş11, G. (2001). Üniversite ögrencilerinin cinsiyet rolleri ve ego durumları arasındaki ilişki, (Yayınlanmamış Yüksek Lisans Tezi), Konya: Selçuk Üniversitesi Sosyal Bilimler Enstitüsü. 
Atış, F. (2010). Ebelik/hemşirelik 1. ve 4. sınıf öğrencilerinin toplumsal cinsiyet rollerine ilişkin tutumlarının belirlenmesi, (Yayımlanmamış Yüksek Lisans Tezi), Adana: Çukurova Üniversitesi Sağl1k Bilimleri Enstitüsü.

Bayhan, V. (2012). Beden sosyolojisi ve toplumsal cinsiyet, Doğu-Batı Düşünce Dergisi, Toplumsal Cinsiyet, 63 (13), 147-164.

Baykal, S. (1988). Üniversite öğrencilerinin cinsiyet rolleri ile ilgili kalıp yargılarının bazı değişkenler açısından incelenmesi, (Yayımlanmamış Doktora Tezi), Ankara: Hacettepe Üniversitesi.

Bekleviç Çelik A. (2017). Bir üniversite hastanesi araştırma görevlilerinin toplumsal cinsiyet rolleri tutum ölçeği ve çalışma yaşamında toplumsal cinsiyet rolleri algısının değerlendirilmesi, Bülent Ecevit Üniversitesi Bilimsel Çalışmalar Dergisi, 29-37. http://cdn2.beun.edu.tr/hemsirelikhizmetleri/2017/01/tek/bilimsel-calisma-dergisi2017.pdf

Buğra, A. (2015). Sosyal politika ve toplumsal cinsiyet çalışmaları: verimli bir birliktelik, (Derleyen: Saniye Dedeoğlu ve Adem Y. Elveren), 2000’ler Türkiye’sinde Sosyal Politika ve Toplumsal Cinsiyet, Ankara: İmge Yayınevi, 13-22.

Bülbül, H. (2014). Erkek kimliğinin oluşumundaki faktörler: iktidar, emek ve arzu, (Editörler: Huriye Kuruoğlu ve Bermal Aydın), Toplumsal Cinsiyet ve Medya, Ankara: Detay Yayınc1lık, 1-16.

Connell, R. W. (2016). Toplumsal cinsiyet ve iktidar, (Çeviren: Cem Soydemir), İstanbul: Ayrıntı Yayınları.

Çelebi, N. (1997). Turizm sektöründeki küçük işyeri örgütlerinde kadın girişimciler, Ankara: Başbakanlık Kadının Statüsü ve Sorunları Genel Müdürlüğü Yayınları.

Dikmen, N. ve Maden, D. (2012). Kadın akademisyenlerin görünmeyen emeği üzerine bir araştırma: ordu üniversitesi örneği, Sosyal ve Beşeri Bilimler Dergisi, 4(2), 235-250.

Dökmen, Y. Z. (2004). Toplumsal cinsiyet sosyal psikolojik açıklamalar, Ankara: Sistem Yayıncilık.

Fine, C. (2010). Toplumsal cinsiyet yanılsaması, (Çeviren: Kıvanç Tanrıyar), İstanbul: Sel Yayıncilık. 
Giddens, A. (2000). Sosyoloji, (Çeviren: İsmail Yılmaz), İstanbul: Kırmızı Yayınları.

Girginer, U. H. (1994). Türk toplumunda cinsiyet rolleri algısl, (Yayınlanmamış Yüksek Lisans Tezi), İzmir: Ege Üniversitesi Sosyal Bilimler Enstitüsü.

Kahraman, L., Kahraman, B. A., Ozansoy, N., Akıllı, H., Kekillioğlu, A. Ve Özcan, A. (2014). Nevşehir hacı bektaş veli üniversitesi toplumsal cinsiyet algısı araştırması, Turkish Studies: International Periodical for the Languages, Literature and History of Turkish or Turkic, Volume 9 (2), 811-831,

Kalaycı, N., Hayırsever F. ve Özcan, F. Z. (2012). İlköğretim okulu öğrencilerinin toplumsal cinsiyet rollerine ilişkin algıları, 2. Ulusal Ĕgitim Programları ve Öğretim Kongresi, 27-29 Eylül 2012, Bolu.

Keith, B. \& Jacqueline, S. (2002). Parent and adolescent gender role attitudes in 1990's great britain, Sex Roles, 7(8), 239-244.

Kimberly, A. \& Mahaffy, K. (2002). The gendering of adolescents' childbearing and educational plans: reciprocal effects and the influence of social context, Sex Roles, 11(12), 403-417.

Marshall, G. (1999). Sosyoloji sözlüğü, (Çeviren: Osman Akınhay ve Derya Kömürcü), Ankara: Bilim ve Sanat Yayınları.

Outhwaite, W. (2003). The blackwell dictionary of modern social thought, USA: Blackwell Publishing.

Öngen, B., Aytaç, S. (2013). Üniversite öğrencilerinin toplumsal cinsiyet rollerine ilişkin tutumları ve yaşam değerleri ilişkisi, Sosyoloji Konferansları, 48(2), 1-18.

Özden S, Gölbaşı Z. (2018). Sağlık çalışanlarının toplumsal cinsiyet rollerine ilişkin tutumlarının belirlenmesi, Kocaeli Üniversitesi Sağllk Bilimleri Dergisi, 4(3), 95-100.

Scott, J. W. (2007). Toplumsal cinsiyet: faydalı bir tarihsel analiz kategorisi, (Çeviren: Aydın Tunç Kılıç), İstanbul: Agora Kitaplığı.

Seçgin, F., Tural, A. (2011). Sınıf öğretmenliği bölümü öğretmen adaylarının toplumsal cinsiyet rollerine ilişkin tutumları, e-Journal of New World Sciences Academy Education Sciences, 6(4), 2446-2458. 
Seyitoğlu D.Ç, Güneş G, ve Gökçe A. (2015). İnönü üniversitesi tıp fakültesi öğrencilerinin toplumsal cinsiyet rollerine ilişkin tutumlarının belirlenmesi, Medicine Science, 5(1), 102-116.

Temel, Z. F. (1991). Yetiştirme yurdunda kalan ve ailesinin yanında kalan 14-18 yaş grubundaki gençlerin cinsiyet rolü tutumları ile moral gelişimlerinin bazı değişkenlere göre incelenmesi, (Yayımlanmamış Doktora Tezi), Ankara: Hacettepe Üniversitesi.

Vefikuluçay, D., Demirel, S., Taşkın, L. ve Eroğlu, K. (2007). Kafkas üniversitesi son sınıf öğrencilerinin toplumsal cinsiyet rollerine ilişkin bakış açıları, Hacettepe Üniversitesi Hemşirelik Yüksekokulu Dergisi, 14(2), 12-27.

World Economic Forum (2018). The global gender gap report-2017.

Yılmaz, D. V., Zeyneloğlu, S., Kocaöz, S., Kısa, S., Taşkın, L. ve Eroğlu, K. (2009). Üniversite öğrencilerinin toplumsal cinsiyet rollerine ilişkin görüşleri, Uluslararası Insan Bilimleri Dergisi, 6(1), 775-792.

Zeyneloğlu F, Terzioğlu F. (2011). Toplumsal cinsiyet rolleri tutum ölçeğinin geliştirilmesi ve psikometrik özellikleri, Hacettepe Üniversitesi Eğitim Fakültesi Dergisi, 40(2), 409420.

Zeyneloğlu, S. (2008). Ankara'da hemşirelik öğrenimi gören üniversite ögrrencilerinin toplumsal cinsiyet rollerine ilişkin tutumları, (Yayımlanmamış Doktora Tezi) Ankara: Hacettepe Üniversitesi Sağlık Bilimleri Enstitüsü. 


\section{Summary}

\section{Statement of Problem}

Gender inequality is one of the most important social problems Turkey faces. Gender roles and attitudes first appear in the family and continue to exist within the educational institution. In order to eliminate gender inequality, teachers who will train future generations have a great deal of responsibility. Based on this reality, it is necessary to first reveal the gender roles and attitudes of teacher candidates. It is not possible for prospective teachers with traditional gender roles to raise an equal gender generation. The aim of this study is to reveal the gender roles and attitudes of teacher candidates and to find out how they have a gender attitude.

\section{Method}

This descriptive and cross-sectional study was conducted between October 01-31, 2018 in Sivas Cumhuriyet University Faculty of Education. As the number of the universe was known in the sample of the study, the sample was calculated and it was found as 350 people. In the research, there are two sections in the questionnaire used as data collection tool, the first part is the Personal Information Form with demographic questions and the second part is the Gender Role Attitude Scale (GRAS) developed by Zeyneloğlu (2008). GRAS consists of 38 items and 5 sub-dimensions. The sub-dimensions are egalitarian gender role, female gender role, gender role in marriage, traditional gender role and male gender role. The data were analyzed by Kolmogorov Smirnov, Mann-Whitney U, for triple and more groups by KruskallWallis $\mathrm{H}$ and Chi-Square tests. The Cronbach's alpha reliability coefficient of the GRAS was found as 0,914 Cronbach's Alpha value for 38 items. As this value indicates that the reliability of the scale is between $0.80<$ and $<1.00$ Cronbach Alpha, the reliability is very high.

\section{Findings}

Of the students participating in the study, 176 (50,3\%) were women and 174 (49,7\%) were men. Considering the family forms that play an important role in the formation of gender role attitudes, $72.5 \%$ of the students in the study live in the nuclear family type. The percentage of students living in extended families is only $23.8 \%$. It stands out that the education level of the mothers and fathers of the participants was quite low.

The majority of the participants (73.7\%) stated that there is an inequality between men and women in Turkish society. Among the findings of the study, it is noteworthy that 187 
(65.4\%) of the 286 people who stated that the reason of the inequality between women and men is the social structure. The percentage of those who express biological differences as a cause of inequality is $5.9 \%$.

The maximum score that students can get from GRAS is 190, which shows that the student has an egalitarian attitude towards gender roles. The lowest score to be taken is 38, which indicates that the student has a traditional attitude towards gender roles. In this study, the mean score that can be taken from the gender role scale is $148,82 \pm 22,47$. This result shows that students have an egalitarian attitude towards gender roles.

According to Table 6, the gender-specific difference of egalitarian gender role subdimension perception was statistically significant as $95 \%$ with its confidence level $(\mathrm{U}=$ 10601,5; p <0,05). Women (Mean Rank = 202.26) have higher egalitarian gender perceptions than men (Mean Rank = 148.43). The findings in Table 6 show that women have a more egalitarian gender role attitude than men in all sub-dimensions. Participants with a missing fragmented family type have higher perceptions (Mean Rank = 245.08) and female gender roles $($ Mean Rank $=220.15)$. Those male students whose fathers are illiterate have lower perceptions of sex role in marriage (Mean Rank =73,06). As can be seen in Table 6, maternal education status does not show a statistically significant difference in gender roles subdimensions.

The most important problems experienced by women are the violence (48.3\%), environmental pressure (47.7\%), gender inequality (34.7\%), oppression and harassment (25.6\%) while for men they are violence (40.8\%), environmental pressure (39.7\%), lack of education (28.2\%), and pressure and harassment (25.6\%) in the street. As a result, the perspectives of women and men about the problems experienced by women are almost similar.

\section{Discussion and Conclusion}

Gender inequality is a problem experienced in different dimensions in our country and in the world. This research aimed to determine the attitudes of students towards gender roles. Previous studies to determine gender roles have generally been made with the participation of students and other professional groups. In this study, it was found that female and male students had egalitarian gender roles in terms of gender roles, but girls have more egalitarian roles than men (Table 5). It is seen that the results of this study are supported with similar studies (Aş11, 2001; Baykal, 1988; Çelebi, 1997; Dikmen ve Maden, 2012; Girginer, 1994; Kalayc1, 
Hayırsever ve Özcan, 2012; Öngen ve Aytaç, 2013; Özden ve Gölbaş1, 2018; Seçgin ve Tural, 2011; Temel, 1991).

In terms of gender equality, qualitative equality should come to mind except for quantitative equality. It is not possible for men and women to have an exact equality in terms of their nature. Therefore, it should be mentioned for the qualitative equality that there must not be a sexual discrimination in using the opportunities, leaving the resources and their use and obtaining the services (Akın, 2007). As can be seen from the findings of the study, there is a difference of attitude towards gender roles among male and female students. The results obtained with this study and the results obtained in the studies of Öngen and Aytaç (2013), Seçgin and Tural (2011), Vefik Uluçay et al. (2007), Yılmaz et al. (2009) are similar.

In this study, approximately three quarters of the students stated that there is a gender inequality in Turkish society and this inequality in general is due to the Turkish community structure. It is a remarkable finding that students have a traditional attitude towards gender roles when their gender role scale and sub-dimension point averages are evaluated according to the maximum score. In the literature, it is seen that the results obtained from the research are supported with other studies when the studies on GRAS and sub-dimensions are evaluated. It is seen that the participants have adopted egalitarian gender roles in the studies conducted by Seçgin and Tural (2011) with teacher candidates, Özden and Gölbaşı's (2018) on health care workers, Çelik Bekleviç and Seyitoğlu's (2017) and Güneş and Gökçe 's (2015) in the health department students. Further studies with larger groups are required to achieve more objective results. 